\title{
THINKING We KNOW MORE THAN WE Do
}

\author{
Louise Barrett \\ School of Psychology, University of Lethbridge, Lethbridge, Canada.
}

louise.barrett@uleth.ca

A Review of the Book

\section{The Knowledge Illusion: Why we Never Think Alone}

By Steven Sloman \& Phillip Fernbach. 2017.

Riverhead Books, New York. 296 pages.

ISBN 978-0-399-18435-2 (Hardback, \$28.00, USD)

Humans are both brilliant and idiotic, write Steven Sloman and Phillip Fernbach at the beginning of the Knowledge Illusion. Having glanced at the newspaper before sitting down to write this, where a tribute to the late, great novelist, Toni Morrison, appears alongside an article about Boris Johnson's Brexit "plans", this seemed all too obvious. Sloman and Fernbach themselves concede that, for the most part, their book is simply stating the obvious: we don't know as much as we think we do; we mistake the knowledge of others for our own; our reasoning is primarily causal, but our causal models are shallow and often wrong. Nevertheless, like many ideas, they say, these ones seem obvious only because we've been made to think about them. When we don't think about them-which is to say, most of the time-we fall prey continually to these "obvious" errors. Most of these errors are largely inconsequential-discovering we don't really know how a zip, a flush toilet or a bicycle work won't stop us from using them effectively (although it's a bit more of a problem when we need to fix those that are broken) - but sometimes the consequences are dire (nuclear testing accidents, plane crashes, and anti-vaccination campaigns all feature). So, what to do? Sloman and Fernbach don't pretend to have all the answers, but their exploration of our cognitive shortcomings, where they come from, and why they matter is thoughtful, provocative 
and pertinent: in our polarized times, when those who make the most noise rather than the most sense dominate public discourse, an insight into the strategies that can work to change people's thinking (and a better understanding of why they fail) was both welcome and offered grounds for hope.

The first half of the book introduces the main argument and offers an evolutionary theory of human thinking. In brief, we suffer from an "illusion of explanatory depth": we overestimate our ability to understand how things work (whether artifacts, biological processes or political systems) because we mistake the knowledge contained in the community as a whole for our own personal knowledge. In other words, the illusion concerns ideas of human individuality, rationality and independence, rather than being a simple matter of thinking we're clever when we're not-although it should be noted that the authors "we" seems largely confined to the population of the USA, where ideas about individualism and independence run rampant. Sloman and Fernbach treat this way of thinking as a human universal, however, and offer their theory of how we ended up this way. Their argument is grounded in the idea that brains and cognitive abilities evolved to enable animals to take more effective action; a notion very much in line with work in socalled 4E cognition (see e.g., Newen et al. 2018). This line of thought is made explicit in chapters 5 and 6, which discuss how humans think with and through their bodies, and also through the environment. They note how humans are much more effective when they can use external aids to memory, and offload cognitive tasks onto the world. From there, it is a short step to exploring how effectively we use other people as stores of knowledge and memory, especially once we evolved the ability to share our intentions and reason about others' mental states. Group collaboration, cooperation, and a division of cognitive labour in various human activities (e.g., large-scale hunting) are argued to be both the key to human success and argued to be the source of our current problems.

These problems arise because our capacity to distribute cognition combines with other cognitive adaptations, namely our abilities to engage in abstraction and causal reasoning, to lead us astray. Abstraction means we don't store all the details of the situations we encounter but only the key elements that lie at the heart of them, so that we can recognise them again in novel situations; causal reasoning allows us to do more than recognise patterns in the world around us, but understand why such patterns exist, and so intervene to change those patterns if we wish. All well and good, but it is precisely the lack of complexity in the big picture and the shallowness of our causal reasoning outside of our domains of expertise that, when combined with the fuzziness of the boundary between our own and others' knowledge, gives rise to the knowledge illusion. We feel we understand something well because we know the knowledge exists and is available, and we don't question ourselves too deeply about whether that knowledge really belongs to us, or whether we simply know where and how to access it. Personally, there are many aspects of this evolutionary account I would question but, however we got here, it's clear that Sloman and Fernbach have identified a key weakness in (at least some) human(s) reasoning.

The second half the book deals with how the knowledge illusion manifests in our daily lives, tackling areas of technology, science and politics. For me, this was by far the more interesting half of the book. In the case of technology, the authors consider why and how simply searching the internet can make us feel like we know things when we don't and the consequences of offloading too much of our cognition onto automated 
systems, like auto-pilots (parts of this chapter are not for the faint-hearted or those with a fear of flying). Part of the problem here, in addition to the knowledge illusion per se, is that we fail to recognise that, unlike other humans, expert systems don't share intentionality - they don't understand what we're trying to accomplish. Instead, we think they "see" the problem as we do, and so understand more than they do. As a result, our GPS ends up directing us toward a cliff. Sloman and Fernbach also argue that "superintelligent" artificial intelligence is already with us in the way that the web and associated technology allow us to create "intelligent machines" through crowdsourcing (Wikipedia being a prime example). These positive developments have to be tempered, however, by the recognition that we understand less and less about how this technology works as time goes on. It becomes more important than ever to recognise exactly what we do and don't know, so that it doesn't all come back to bite us.

The public understanding of science also provides fertile ground for the application of the knowledge illusion. If we don't really understand how toilets and zips work, what hope is there that we'll have a clear and coherent understanding of the causes of climate change? Here, the authors focus on the so-called "deficit model", which suggests that a lack of knowledge explains anti-scientific attitudes. Give people the knowledge they lack, so the thinking goes, and their attitudes will change. Except they don't. Sloman and Fernbach explore this by drawing on their insight that our knowledge is, in large part, not ours at all, but spread across the community as a whole, and tangled up with the complex of other beliefs and values held by the community. Giving people more facts does nothing to shift their views, because their views are not based on the rational assessment of facts but on how these facts gel with the other values and beliefs of the community. Sloman and Fernbach also bring in our faulty causal models, where we base our understanding on similarities to our direct experience (so we assume the effects of caffeine get used up faster when we work hard on a task, in the same way we use more petrol when we drive uphill). Their argument is that we need to understand and then correct the causal models people bring to bear on particular scientific facts, and not just stuff ever more facts into them.

As one might expect the politics chapter is extremely timely, and here the authors again highlight the importance of causal reasoning in helping to change attitudes. Studies asking people to think through the consequences of a particular policy tends to reduce extremism much more than asking people to give reasons for why they hold a particular position. This is because a causal account of a policy's likely effects is much more likely to shatter a person's illusion of understanding, so weakening the strength of their views on a particular issue. Of course, things aren't quite that simple: shattering illusions is equally likely to make people turn away from learning more about an issue precisely because they don't like having their illusions shattered. Equally, a causal understanding doesn't help when a particular policy proposal enshrines a "sacred value": if you believe abortion is always and everywhere morally wrong, thinking through the consequences of a ban on abortion is unlikely to shift your attitudes one iota. Sloman and Fernbach thus make no pretence that consequentialist reasoning can solve all the problems of political polarisation and extremism. They do us all a service, however, by pointing out how politicians use sacred value arguments to weasel their way out of the harder and more complex issue of explaining why a particular policy will work. 
Sloman and Fernbach conclude with some thoughts on how we might redefine what it means to be smart (moving away from "great man" narratives of achievement, and instead assessing how individuals contribute to the success of their teams and communities); how to make people smarter (create communities of learning, in which it becomes clear how we use knowledge with and through others) and how to make smarter decisions (a lot of "nudging" and libertarian paternalism-I'm less sure about this one... ). No magic bullets, no panaceas, but I felt more hopeful after reading these sections than I have for a while. To be honest, I wasn't expecting to like this book as much as I did. Or rather my expectations rose and fell as I read. I picked it up with some enthusiasm, given my great interest in embodied and distributed views of cognition. I then felt a bit deflated after the first few chapters where it seemed these more embodied views were being bent to fit a standard cognitivist story (all the abstraction and whatnot)-- maybe this was because I thought I knew more than I did, or that I knew better than the authors. Maybe my own knowledge illusion was getting in the way. Whatever it was, I was increasingly won over as the book progressed. By the end, I was making notes all over the place, vowing to reform my teaching, and thinking up my own ways to test how people understand science. We think so we can act more effectively, the authors say. Indeed, we do.

\section{ABOUT THE AUTHOR}

Louise Barrett is Professor of Psychology and Canada Research Chair in Cognition, Evolution and Behaviour at the University of Lethbridge, Canada. She works on the social behaviour and ecology of human and non-human primates.

\section{REFERENCES}

Newen, A., De Bruin, L., \& Gallagher, S. (Eds.). (2018). The Oxford handbook of 4E cognition. Oxford University Press. 